\title{
Desiring Connection: Affect in the Embodied Experience of Kizomba Dance
}

Tiffany Pollock

YORK UNIVERSITY

Kizomba is a partnered social dance originating in Angola that is rapidly gaining worldwide attention, particularly in Europe and North America. Discussions and advertisements about kizomba employ words such as 'connected,' 'sensual' and 'intimate,' creating dance experiences and a wider scene laden with affect and an underlying eroticism. New and non-dancers often interpret kizomba as sexual or sexy, and, like other dances that have moved transnationally to the West, kizomba is crosscut by issues surrounding relations of sexuality, race, class and gender. This autoethnographic paper draws on my embodied experiences of dancing kizomba to consider the multifaceted types of cultural work that dancing does. With an attention to affect and the desiring intensities that are bodied forth on the dance floor, kizomba, and its affective sphere, is (re)explored outside of critical frameworks of analysis. By delving into the feelings that arise during the dance, the paper demonstrates what kizomba does to bodies, and what bodies do, in turn, with kizomba. While the adoption of kizomba in the West can reinforce problematic ideologies, the types of sociality offered through dance are also transgressive of hegemonic and normative social institutions. Kizomba, it is argued, offers a site to reimagine what it means to be self/other, sexual and connected.

\section{KEYWORDS}

Dance, Affect, Embodiment, Sexuality, Autoethnography 
A gentle touch, the smallest gesture of a hand pressing rhythmically into the small of my back, illuminates my entire body which is open to sensations. Lungs expand to breathe in my partner and our breath aligns with the beat. Stomach muscles contract under skin. I wait for a thigh to rub against mine to direct me to move. I feel for our energy, transmitted through connections at our chest, hands, and temples. Continually working to transfer our weight with a never-ceasing skin-to-skin connection, we are getting there. I can feel us dropping deeper. More intense energy comes from their body as their arm tightens around my back. My body tenses as they grab me and move me three fast steps backwards. Pause. They take my leg between theirs, isolating my hips and twisting our lower bodies to the right. Pause. We wait. They place my arm around their neck, tracing its contours and sliding all the way to that spot on my lower back. A small burst of sensation follows. Only the smallest movements keep us dancing. This is kizomba connection.

This paper reflects on my embodied experiences, as a white Canadian female, dancing kizomba, an Angolan partner dance that is rapidly gaining worldwide popularity. ${ }^{1}$ The kizomba rhythm and movement is derived from an up-beat Angolan genre called semba, meaning "a touch of the bellies," which is a characteristic posture of the dance. Semba became popular in Angola in the 1950s but began to change during the 1980 s as Caribbean rhythms such as zouk traveled back to the West coast of Africa. The slower and calmer rhythms merged with semba to create kizomba, and the dance took on a different feel, becoming "more intimate, sensuous, and slower" (Oyebade 2007, 156). As kizomba has moved through other Lusophone countries and beyond, elements from R\&B, tango, hip hop, zouk, dancehall, Afro house, and tarraxinha, among others, have created diverse fusions. ${ }^{2}$ Kizomba's reterritorializations in Europe and North America have typically happened through pre-existing Latin dance scenes, giving birth to the European style, which I have studied most extensively. European kizomba is danced to slower, bass-heavy, zouk-inspired music and employs a very close embrace between (typically) male and female partners, although women often dance together, as well. The kizomba I participate in is for social dance purposes, as opposed to performance, and over a three-year period I attended dance lessons and socials where people move to music mixed by a kizomba DJ in a participatory atmosphere. The socials are attended by people of diverse ages, ethno-cultural, and racial backgrounds, and typically have thirty to fifty people in attendance.

Creating connection, sometimes called "kizz connection," with one's dance partner is at the heart of the European social style. People will usually dance at least two songs together before switching partners to try and establish some degree 
of affective connection. In some kizomba encounters, a very intense connection can be brought forth which is so overwhelmingly enjoyable that it is not uncommon to see two people dance as many as ten songs together if they have found "it." While not every dance has the same level of intensity, those heighted dance experiences are sometimes referred to as reaching "deep kizomba." Discussions about kizomba connection tend to be inflected with utopian sentiments, which Western dance studios, teachers, and socials play on: "This dance is all about connecting the mind, body and soul: moving as one” (Steps Dance Studio). Given these sentiments, and the style of the dance, new and non-dancers often interpret kizomba as sexual or sexy, but, "It's not about that," teachers maintain. ${ }^{3}$ The debate about whether kizomba is sexual or sensual is an infamous point of discussion, and kizomba's sensuality (rather than sexuality) is almost always highlighted and officially encouraged. I have, however, seen people kissing, caressing, and grinding to the beat on many occasions, and I have experienced dances that cross the precarious boundaries between sensual enjoyment and a sexual encounter. In turn, dance socials and lessons often utilize this underlying erotic potential with titles that play on the slippage between kizz and kiss, such as the "Kiss to Kizz Kizomba Night and Workshop" (Bailemor De). One gets the sense that there is some transgressive potential that creeps at the edges of the of the dance, even if it is carefully controlled with (sensual) language and notions of appropriate technique and posture, such as a straightened frame which ensures that groins will not touch.

My initial inclination when I began to dance kizomba was to critically analyze what I felt was a fetishization of 'connection' as a romanticized colonial and Eurocentric notion that invokes sexuality, race, gender, and class in problematic ways. Dances that have moved from marginalized, and often black, communities to Western centers typically undergo problematic processes of change as they are appropriated, approximated, and assimilated (Dixon-Gottschild 2003, 21). The techniques, postures, and ethos of dances such as salsa, bachata, tango, and rumba, among others, have been "refined" through straightened frames and codified steps, and de-sexualized to meet the ideals of white Western acceptability (Cresswell 2006; Delgado \& Munoz 1997; Desmond 1997; Dixon-Gottschild 2003; Garcia 2013; McMains 2006). These dances, however, are also often inscribed with sexuality for marketability; discourses that employ words such as "hot," "intimate," "connected," and "fiery" to describe dances, and particular movements, are produced through colonial desires to consume and experience Othered emotionalities and sexualities (Bosse 2008; Desmond 1997; McMains 2006; Savigliano 1995; Tornqvist 2013). The adoption of these partnered dances in the West, it is argued, reproduces desires for racialized, heterosexist, and heteronormative versions of coupling, masculinity, and femininity (McMains 2006; Schneider 2013). ${ }^{4}$ 
I am confident that a critical analysis of the European style of kizomba, and kizz connection, will uncover similar problematic dynamics. Indeed, an ethnography of the Dutch kizomba scene finds that the dance is a stage for white dancers to reproduce racialized and sexualized imaginaries (Belijaar 2016). Critical studies of social dance, like those cited here, have typically analyzed discursive representations and envisioned bodies as 'social texts' that signify particular meanings and form relations within pre-constituted forms of power (Desmond 1997). While important, these perspectives tend to reduce the materiality of the body, often to its visible physical form, without fully taking into account the complexity of the felt components of bodily movement and embodiment. As Kelly (2014) argues, the ephemeral and affective sensations experienced and produced through dancing bodies are themselves generative of culture, power, and connectivities. Thus, the dancing body's expressivities must also be considered as part of the body's productive corporeality. While conscious of the ways in which kizomba is problematically represented and adopted in this new context, exploring the feelings of a body doing kizomba offers a more nuanced view of the cultural work that happens on the transnational dance floor; attending to danced sensations reveals how people learn to negotiate feelings in conversation with other bodies, experiences, and memories.

McCormack (2014), in his work on the coproduction of moving bodies and spaces, contends that researchers should avoid framing events or objects of study through a pre-defined issue that renders a particular judgment. Instead, and following Massumi's notion of exemplification (2002), he suggests employing a framework that is able to capture what is "unruly and excessive" of examples $(2014,12)$. Employing exemplification as an approach to study movement practices requires "a sense of the specifics of participation while also holding onto the possibility that participation has the potential to transform the sensibility that shaped it in the first place" (McCormack 2014, 12). In the context of kizomba, this entails delving in to the bodily intensities of movement to understand what is in excess of some of the issues uncovered with critical analyses. Thus, I focus on the affective ephemera of dance as important 'specifics of participation' to develop an in-depth exploration of what kizomba sensations do to bodies, and what bodies, in turn, do with these sensations. The approach should not be viewed as one that seeks to forget the critiques, and my own whiteness. Rather, these aspects should be held in tension with the discussions here. 
This research is centered within my body and follows the insights of dance scholars who use the moving body as a primary tool of research (Potter 2008; Sklar 2000, 2001). ${ }^{5}$ The methodological approach centers on kinesthesia, a sense of feeling one's body in motion (Potter 2008, 449), and a proprioceptive awareness which is "the reception of stimuli produced within one's own body, especially in movement" (Sklar 2000, 72). I do, however, deepen this corporeal awareness and focus not only on the movement of my muscles and bones, but also on those affective intensities that arise through dancing. In conceptualizing affect, I follow scholars who are influenced by the work of Spinoza, such as Deleuze and Guattari (1987) and Brian Massumi (2002), and others who build off that work (Brennan 2004; Gould, 2009; Gregg \& Seigworth 2010; Manning 2006, 2013), and view affect as an intensity that moves a body to action or to inaction. Affects are often discussed as pre-cognitive sensations that differ from emotions which attempt to capture felt intensities to bring them into the realm of socio-cultural meaning (Massumi 2002, 28). Importantly, while affects are produced by bodies, they are not only contained within them; they are dynamic and move among and between bodies, destabilizing notions of discrete and static subjects (Brennan 2004; Henriques 2010; Manning 2013). While affect is physiological, it has the potential to become disembodied and static when rendered in text. Dance, similarly, can cease to be an event of unfolding experience as it is given a discursive structure. This stasis can result in murky theories and unaddressed questions, particularly surrounding what affect does, and how exactly it moves a body. To this end, I invite readers into the embodied dance experience, and I continually draw attention back to the feeling of kizomba by interspersing narratives of my body dancing throughout. ${ }^{6}$ While recognizing that my bodily experiences are different from others', this affectively attentive approach demonstrates how dancing offers opportunities to (re)negotiate bodily tendencies and memories (Fuchs 2012; Massumi 2002), and to develop new capacities to affect and be affected (Latour 2004). These capacities open bodies up to the inter-embodied nature of being, that is, the relationality that shapes social worlds both on and off the dance floor.

\section{'Acquiring' Kizz Connection}

I straighten my frame and pull up my body to move into the "hug" embrace. I concentrate on feeling the 'intention' of my partner, as teachers say. I try to focus on the energy transmitted through our sternums. My thoughts take me away: Is my position correct? Where should I place my arm? Can they feel the nervousness flowing through my body? My muscles want to pull away and make a slight barrier between our touching. My partner leans in closer and I 
drop deeper into our bodies. I move my concentration to their temple against mine, so I can feel the connection. There is an excited and quiet vibration. The DJ starts and the pulsations of the kizomba beat vibrates through my body: feet, legs, knees, hips, belly, spine, ears. It moves the excitement through me: Oooom ga Gaa ga, Oooom ga Gaa ga. A thigh muscle twitches to signal for our bodies to pull up together with the rhythm. The long drawn out first beat as we both push off the floor feels like caramel being pulled from the ground. Close your eyes. Relax. Drop. Feel. Their hand presses on my back to signal which way my body should move. I tingle, and my body is on edge from this small bit of contact. They continue guiding me through this small piece of back. My legs drop from my body and I am only my back. I fall deeper into my tingling skin and our connection.

Discussion of "connection" is not simply a discursive fetishization; it is an essential modality for dancing kizomba and a prism of dance floor feeling. The embrace employs much body-to-body connection through touch-chest, bellies, temples, hands, thighs, knees, arms-and requires a heightened sense of kinesthesia and proprioception in order to move with your partner. There are few predictable patterns and the lead has a near-endless repertoire of combinations to draw on. Because of the closeness of the embrace, one cannot rely on visual cues and must be hyper-aware of, and responsive to, their own and their partner's body to interpret and respond to the most minute changes, anticipations, and hesitations. As a follower, I must be with my partner in a more focused way than in other partner dances I have studied, such as salsa and bachata, for instance. My attention is in our muscles, bones, breath, and skin. Many of us close our eyes to better attune to the marginalized senses-smell, touch, taste, sound, motion-which assist in our kizz connections.

Dancers develop a "felt bodily knowledge" (Sklar 2000, 70). This way of knowing is not solely centered in feeling and enacting correct movements, but, as Parviainen relates, dancers become more "bodily sensitive" to the qualities of movements (Parviainen 2002, 20). The drawn-out feeling of the caramel-like pull of legs in the kizomba step is known precisely this way, as is the way I straighten my back and elongate my neck as I move into the hug embrace with my partner. I am sensitive to where my body is connecting and how the speed at which I place my hand around their neck will affect our dance. This sensitivity helps form connections, but it extends beyond touch and bodily movements, and into the territory of affect as we feel for the smallest of shifts of intensity in our bodies. 
Kizz connection is an affectively somatic way of knowing. Bodies connected through kizomba learn to engage with intensities in new ways and develop a greater awareness of, and sensitivity to, those split-second firings of affect that make our bodies move, act, and feel. Latour (2004) argues, in the context of scent, that bodies must learn to be affected, and that certain body parts are "acquired" as they tune in to this realm of experience (Latour 2004, 207). The kizomba body "acquires" sensitive skin, muscles, and veins as blood and hormones rush to respond to sensations. It is a body that feels its reactions in relation with other bodies, deep inside the visceral experience of movement. I had to learn to feel my body in this more sensual way. In the beginning, it was semi-connected, and not yet fully engaged in the movements of affect that rise up. At times, thoughts about my moving body would pull me out of this deeper sensual engagement. After a year of dancing, I was able to drop into my body and attend to the expressions of muscles twitching, the chills on my skin when the perfect intensity builds, the surge of excitement in my belly or the movement of 'intentions' through our sternums. This is a more deeply attentive proprioception that registers not only the movements of muscles, skin, and joints, but also ephemeral expressions and their qualities. While affects are pre-cognitive essences, they are nevertheless felt (Massumi 2002). The minutia of intensities working on and through our dancing bodies are registered and stored in our physical knowledge. It is how I know to feel at spots such as the temple or my lower back for an excitement that might reside there and enact a bodily response that will complement the affect of my partner. The visceral sensations that instantiate the responses are not necessarily named or categorized, but they are known-sometimes as tingling skin-and stored in our bodies to be recalled again when creating connections. In this learning to be affected, my body became more "articulate" it its ability to affect and act in response to new differentiations and sensations (Latour 2004, 210). This type of affective communication is paramount for the bodily navigation of kizz connection, particularly given its erotic potential.

\section{Deeper Kizomba}

They take my hand. The connection is there immediately in our fingers as we walk together to find a space. Our bodies remember from before and move into our comfortable hold. I keep my eyes closed and feel for themthe gentleness of their touch, a deep inhalation, a spark that passes through their temple to mine-to gauge the depth of our dance. They subtly walk me through different steps and back towards our corner, where we "went deep" 
before. It envelops us. They stop me and draw up in the slowest kizomba step. And again. My back releases my upright posture and the weight of my body rests on their temple. Energy sparks in my core. I move my thigh closer and brush harder against my partner's. Our hips move forward, and I anticipate the brush from our groins. I can FEEL them, and I grind my body there again. The rules from lessons wake up my mind: keep your upper body stiff; "this is not a sexual dance; it's not about THAT." I shouldn't be doing this! But, I fall back into our bodies and we rub up against each other again, slowly and methodically. My skin flushes with the smallest quivers of nervousness, but we continue into the deepest kizomba.

"This is not a sexual dance. It is a sensual one," teachers and dancers must officially say. Yet, experiences, movements, and affects leak outside of these neat renderings. I recognize these discussions as ways in which people struggle with how an Angolan dance gets articulated as "sexual," and how invoking "sensuality" helps to express some of the intensities that are felt. But, of course kizomba can be sexual. Sensations arise, postures slip, groins brush, and people are moved in ways that do not neatly align within the boundaries of acceptable connections. Any movement practice where people share time, space, and bodies has the potential to invite a multiplicity of bodily feelings, some of which may be erotic. While I cannot speak for other dancers' sensations, and the meanings they draw from them, I have witnessed and felt dances that cross back and forth over the constructed line between sensual and sexual feelings. Indeed, most kizz connections I experience float on this precipice, changing moment-to-moment.

Kizomba connection is primarily a felt experience, and thus it requires us to think through its moments of eroticism outside of strictly representational frameworks that analyze how sexuality operates through discursive spheres of meaning. For Deleuze and Guattari, sexuality is understood as a field of intensities through which it is "transformed from a 'dirty little secret' into a productive energy" (Beckman 2011, 9). This stands in contrast to the ways it has been internalized, relegated to the privacy of the couple and pathologized (Foucault 1978). Deleuze and Guattari use the concept of 'desire' to communicate the productiveness and dynamism of such felt intensities (1983). Desire is not always erotic, although it can have a sexual component; this is not, however, created from lack nor is it always oriented toward specific objects. Desire is a free-form affect that initiates movement, change, and connection. It "naturally seeks multiplicity and creation," and establishes relations among bodies, objects, or other desires so as to proliferate its flow (Goodchild 1996, 5). Desire is a bodily experience tied to a whole field of sensations that push and pull bodies to align and move with others on the 
dance floor. To desire is not to be drawn towards an object, but "to be drawn into another world expressed by that object” (Kerslake 2010, 51). To desire in kizomba is to desire the feeling of connectivity, in whatever form that may take. It is the affective glue of kizz connections.

Thinking through desire in kizomba opens up space to view what is in excess of the issues surrounding sexuality in the adoption of transnational dances. Rather than position kizomba as another example of sexualization, there is much to be explored in the affective corporeality of danced desire. As referenced previously, the corporeal turn in dance tends to bracket out the sensational ephemera of the body and embodiment (Kelly 2014), and research at the intersections of dance and sexuality has, in turn, not fully engaged with the feelings of eroticism (i.e. Hannah 2010). ${ }^{7}$ Approaching danced sexuality as a bodily experience-of desiring intensities-offers insight into how eroticism is produced and negotiated through bodily performances on the dance floor. We can attend to the shifting nature of dance floor encounters without drawing a boundary between sexuality and sensuality; kizz connection can be both sensual and sexual. The meaning of movements and sensations, as they are brought into consciousness, shift and change throughout the dance. It may begin as a shallow kizz connection, and through a small spark or a sensed memory in the room, shift to a different desiring feeling that engenders a different connection. Importantly, the body is the site where these intensities connect, and where the flows of desire are shaped and negotiated.

Expressions of, and reactions to, desire are part of our affective bodily knowledge and memory (Fuchs 2012). Fuchs states that the body is "the ensemble of organically developed predispositions and capacities to perceive and to act, but also to desire and to communicate. Its experiences, anchored in body memory, spread out and connect with the environment like an invisible network, which relates us to things and to people" $(2012,11)$. Our bodies enter the dance floor with particular tendencies for how they will desire that are built into a body's past (Massumi 2002). For some people, kizomba might entail a (re)learning of how to connect with others in a deep way. Developing new bodily capacities to affect and be affected, and to feel and move with flows of desire are part of this (re)training. While it is undirected, our bodies learn through desire, and come to remember how to differently connect with people and dance spaces. Our dances, and the depth of kizz connections, become embedded in bodily memories held in the skin, bones, muscles, and organs, and also in our affective and sensational circuitry. Certain sensations might draw us back to a previous experience that influences our dance. Particular spaces, smells, movements or partners might come to encompass an erotic pull or a familiar comfort that is danced back into being. An instant deep kizz connection, fueled by a particular corner of the room or the 
faint smell of someone's skin, is brought forth each time our bodies remember. "Body memory does not represent the past but re-enacts it" (Fuchs 2012, 19), and thus we (re)live and (re)produce desires through a sensational bodily remembering.

Given the porousness of kizz connection, and the unknown tendencies and pasts of the bodies we are desiring with, negotiating this expressive unfolding requires astute affective communication. My deep proprioceptive awareness is fully engaged to feel the inner sensations of my body in response to my partner's. Our temples, pressed against each other, is a space I return to in an attempt to enter this realm of attunement; my head is usually buried in the side of their face with a hand on their chest to catch a passing vibe, so as to feel the flow of our desire. This sensational communication is how we slightly adjust our kizomba movements so we can push into or pull away from particular desiring encounters. Of course, we do not always do this correctly, and I have certainly had uncomfortable dances and initiated movements that have made others hesitate. But, importantly, dance is a way that we learn to adapt our bodily enactments of these affective expressivities with others. In so doing, we expand our own capacities to desire comfortably and safely. This type of affective knowledge and memory-building, and the bodily sensitization it requires, has ethicopolitical potentials in that we are exposed to new ways to feel our bodies with others. Our materiality is opened to new modalities as we "acquire" (Latour 2004, 207) a body that is aware of its desiring entanglement with others.

\section{Becoming Undone}

Every gesture before the dance begins is drawn-out and in-line with the rhythms that float in the room. The summer heat washes over tired moving bodies, making for an especially slow and sensuous night. There is a smoothness with which we follow our leads to the floor. The DJ begins, and the sound melts us. I collapse into my partner, close my eyes and tune in. Flickers of excitement in quiet bodies. We feel with each other, and our desires, to create a connection. Our bodies slow down together-simple, repetitive rhythms. A surge of intensity rages up through my feet and into my belly. They feel it too; I can sense it in the way we wait and breathe together. Our sweat soaks our chests. Our bodies respond to our muscles and vibes, moving before a thought actualizes, before it travels to and from the skin. Only response. I am in my partner's chest, breathing with them and taking their rhythm inside me. I am in their hand, which melds into my shoulder. I am in my left arm which wraps around and fuses with the back of their neck. I feel 
our belly as the center of our collective. We are becoming undone, drifting deeper and deeper inside each other and those surrounding us as the sounds, smells, tastes, and energy of the room entangle our bodies. I can feel the buzz of others around us. We feed off it in our small piece of the dance floor.

Social assemblages are formed through desire, which Bonta and Protevi refer to as "the material process of connection, registration, and enjoyment of flows of matter and energy coursing through bodies in networks of production in all registers, be they geologic, organic, or social" $(2004,76)$. Desire connects all dancing bodies in the space. It does not only draw us toward different depths of encounters with a dance partner but brings forth a dancing collective through which we are offered opportunities to (re)imagine self and other. People seem to touch in specific ways on certain nights in the dark lounges of socials. The DJ feels the crowd and creates mixes that encourage particular intensities and qualities of movement, which work to generate the dance space (McCormack 2014); together we build the feeling of the atmosphere (Brennan 2004). Sensing and responding with the flows of desire and movements in the room allows one to experience the self as part of a larger formation in which bodies, affects, and space are co-constitutive, unstable, in-flux, and connected. We become what Henriques (2010) refers to as "an entirely corporeal, but at the same time collective subject" (2010, 67). Sounds, vibrations, and desiring intensities extend beyond the individual and into the atmosphere, creating larger entities of connected kizomba dancers. I often feel for others around me and can sense how deeply they are in their connections, which influences my own. In these sensual entanglements, we glimpse the instability and undoing of our bodies as we become an "open, fluid and multiple whole" (Henriques 2010, 67).

Manning (2006) argues that moving with others showcases the relational nature of being. She states, "Sensing bodies in movement are not individual bodies; their individuations are always collective" (2006, xviii). Becoming attuned to, and feeling with, kizomba's desire opens us to the relationality through which bodies and subjects emerge as a "one" that is also a "many," that is, a body that is always "more-than its taking-form" (Manning 2013, 19). Manning states, that "the body cannot be seen as that which holds together across space and time in a kind of beyondness of the event. Body is event, known as such only in the collusions of a process shifting" $(2013,18)$. In dance, as we take each other in-through sounds, vibrations, energies, sweat, smells, tastes, touches-we disrupt our-selves and feel the wider collective through which we eventfully emerge (Manning 2006, 2013). In some dances, I can feel not only a sense of being "in" a particular part of my body, as I concentrate on feeling sensations there, but also as being "in" my partner's body, or as a small node through which desire moves in the dance floor collectivity. This is not to say that a self or a discrete body disappears, but rather, 
that the process of forming and reforming is registered. In kizz connections, we disrupt Eurocentric constructions of the person as a self-contained and individual entity, and are offered opportunities to feel our inter-embodiment, that is, the relational nature of our being-in-the-world.

Inter-embodiment is not a utopian revelation of shared subjectivities or experience (Ahmed and Stacy 2001). It is also a way of understanding differentiation as diverse bodies emerge in relations of power and in assemblages that categorize in particular ways. Manning employs touch in tango dance to showcase this fraught relationality and its ethicopolitical potentials. She contends that "Touch is an ethical discourse" (2006, 9); bodies reach toward each other "each time challenging and perhaps deforming the body-politic, questioning the boundaries of what it means to touch and be touched, to live together, to live apart, to belong, to communicate, to exclude" $(2006,9)$. Like the touching of skin in dance, shared affects and expressivities of desire are forms of reaching toward and touching. Each kizz connection offers moments to ponder and remember-through our bodies-our mutual emergences and movements in different spaces. Dancing kizomba is a reminder not of an intertwining equality, but rather, that we are not "structurally equivalent...but in a relation of asymmetry and potential violence" (Manning 2006, 48). Connecting through desire, thus, entails responsibility.

\section{Desiring Potentials}

In kizomba, desire connects us across spectrums of social difference. Dance socials have an incredibly diverse collective-in terms of race, class, ethnicity, age, sexuality, and nationality-and we are given opportunities to reimagine the self and the social (Hamera 2007). What is important here, and what many critical studies of social dance gloss over, is that dance floors are spaces in which people come together across various categorizations to practice sensing, responding and emerging with each other. Hamera posits that dance communities foster 'queer intimacies' for the ways in which they bring diverse groups of people, who may not otherwise interact, into contact and conversation (2007). Technique functions as the "social and aesthetic bedrock" through which they engage (Hamera 2007, 18). Technique in kizomba extends beyond movement and posture, in that we develop capacities to desire and connect together in ways that might be unimaginable in other social realms. Ideologies persist within official kizomba 
technique to police how our bodies should engage, feel, and align. Attempts are made to orient desire and control its proliferation. Technique, however, is molded to stretch these protocols of sociality and to manifest the affective intensities and connections of desire we produce. We use the "diversions and reappropriations [that] hide in the light of official syllabi, training regimens, and spectatorial practice, redeploying technique in service of relationships and fantasies that ideal, strategic visions of the body could not, or would not, condone" (Hamera 2007, 22). Desire is delinked from the individual on the social dance floor; it circulates in the room changing and moving our bodies, allowing us to responsibly shape our dances and the collective experience. Given how this knowledge becomes embodied, we must consider how these experiences and new capacities might be more than fleeting moments of affective attunement and negotiation, but that they may be productive and generative in social sites and spaces beyond the dance floor. How might "learning to be affected" (Latour 2004) through dance (re)shape practices and interactions in the everyday eventfulness of being with others? How might moving and desiring with others expand our embodied knowledges, and thus, our capacities to be with others in more responsible and meaningful ways?

Reading kizomba through a deeper bodily engagement does not make politically problematic elements disappear. What this approach demonstrates, however, is that the act of dancing might be a transformative experience that can destabilize normalizing notions surrounding sexuality, bodies, and social difference. Attending to the body's deeper corporeality-one that includes the affective sensations of movement-provides insight into the different ways that people relate, interact, socialize, and encounter each other through bodily performances. At each dance social, we come together to share affects, bodies, fluids, touch, hormones, movement, and rhythmic musical vibrations; we take each other in and we push the boundaries of what it means to be self/other, connected, sensual, and sexual. These elements of dance experience are what leak outside of examples. Through this excess, the transnational dance floor, and the bodies that coproduce its space, become sites of potential for the production of alternative socialities that are brought forth through shared desires, and affectively-attuned knowledges and memories.

\section{Endnotes}

1. Oyebade (2007) notes that there are debates about whether kizomba is originally from Angola or Cape Verde, but it is widely referred to as Angolan in the dance scene.

2. In the Netherlands, Belijaar notes that kizomba has become an overarching term for many styles of music such as the slower Cape Verdean cabo-love, cabo-zouk, ghettozouk $(2016,41)$. This parallels the descriptions in the scene I have danced in.

3. All quotes that are not cited are stock phrases I have learned at public lessons, socials and in 
online forums.

4. The male-female formation which we see in the majority of social dances is a colonial import to West Africa, where historically there was a preference for separate-sex or non-partnered dancing (McMains 2006, 116).

5. I recognize that the experience of my body doing kizomba will be different from others and do not purport to speak on behalf of all dancers' bodily experiences and the meanings they garner from them.

6. I am inspired by Stewart's (2007) approach in Ordinary Affects, in which she relates the textures of the everyday through combining storytelling, critical analysis, and observation.

7. Two scholars do briefly acknowledge sexuality as a felt experience that can be enhanced by movement in the context of club cultures (see Jackson 2004 \& Tan 2013).

\section{References}

Ahmed, S. and Stacey, J. (2001). Introductions: Dermographies. In: S. Ahmed and J. Stacey, eds., Thinking Through the Skin. London and New York: Routledge, pp. 1-19.

Bailemor De. (2016). Events. [online] Available at: http://www.bailamor.de/event/ kiss-to-kizz-kizomba-night-and-workshop.html [Accessed 20 Oct. 2016].

Beckman, F (2011). Introduction: What is sex?: An introduction to the sexual philosophy of Gilles Deleuze. In: F. Beckman, ed., Deleuze and Sex. Edinburgh: University of Edinburgh Press, pp. 1-28.

Belijaar I. (2016). Body Politics: The Social Production of Difference in the Dutch Kizomba Dance Scene. Apeldoorn and Antwerpen: Het Spinhuis.

Bonta, M. and Protevi, J. (2004). Deleuze and Geophilosophy: A Guide and Glossary. Edinburgh: Edinburgh University Press.

Bosse, J. (2008). Salsa Dance and the Transformation of Style: An Ethnographic Study of Movement and Meaning in a Cross-Cultural Context. Dance Research Journal, 40 (1), pp. 54-64.

Brennan, T. (2004), The Transmission of Affect. New York: Cornell University Press.

Cresswell, T. (2006), "You cannot shake that shimmie here”: Producing Mobility on the Dance Floor. Cultural Geographies, 13 (1), pp. 55-77.

Deleuze, G., \& Guattari, F. (1983). Anti-Oedipus: Capitalism and Schizophrenia. 
Minneapolis: University of Minnesota Press.

Deleuze, G. and Guattari, F. (1987). A Thousand Plateaus: Capitalism and Schizophrenia. B. Massumi (trans.). Minneapolis: University of Minnesota Press.

Desmond, J. C. (1997). Embodying Difference: Issues in Dance and Cultural Studies. In: C.F. Delgado and J.E. Muñoz, eds., Everynight Life: Culture and Dance in Latin/o America. Durham: Duke University Press, pp. 33-64.

Dixon-Gottschild, B. (2003). The Black Dancing Body: From Coon to Cool. New York: Palgrave MacMillan.

Foucault, M. (1978). The History of Sexuality volume 1: An Introduction. R. Hurley (trans.). New York: Pantheon Books.

Goodchild, P. (1996). Deleuze and Guattari: An Introduction to the Politics of Desire. London; Thousand Oaks: Sage.

Gould, D. B. (2009). Moving Politics: Emotion and ACT UP's Fight Against AIDS. Chicago: University of Chicago Press.

Gregg, M., \& Seigworth, G. J. (eds.). (2010). The Affect Theory Reader. Durham: Duke University Press.

Hamera, J. (2007). Dancing Communities. New York: Palgrave MacMillan.

Hannah, J. (2010). Dance and Sexuality: Many Moves. The Journal of Sex Research, 47 (2-3), pp. 212-214.

Henriques, J. (2010). The Vibrations of Affect and their Propagation on a Night out on Kingston's Dancehall Scene. The Body and Society, 16, (1), pp. 57-89.

Fuchs, T. (2012). The Phenomenology of Bodily Memory. In: Koch, S. C, ed., Body Memory, Metaphor and Movement. Amsterdam; Philadelphia: John Benjamins Pub. Co., pp. 9-22.

Garcia, C. (2013). Salsa Crossings: Dancing Latinidad in Los Angeles. Durham: Duke University Press.

Jackson, P. (2004). Inside Clubbing: Sensual Experiments in the Art of Being Human. Oxford; New York: Berg.

Kelly, E. (2014). Towards a Generative Theory of Politics of Expression: Re-negotiating Identity in the 'traditional' Dances of Fiji and Fiji's Canadian Diaspora (Doctoral dissertation). University of York.

Kerslake, C. (2010). Desire and the Dialectics of Love. In: L. De Bolle, ed., Deleuze and Psychoanalysis. Leuven: Leuven University Press, pp. 51-82. 
Latour, B. (2004). How to Talk about the Body? The Normative Dimension of Science Studies. Body \& Society, 10 (2-3), pp. 205-229.

Manning, E. (2006). Politics of Touch: Sense, Movement, Sovereignty. Minneapolis and London: University of Minnesota Press.

Manning, E. (2013). Always More than One: Individuation's Dance. Durham: Duke University Press.

Massumi, B. (2002). Parables for the Virtual: Movement, Affect, Sensation. Durham: Duke University Press.

McCormack, D. P. (2014). Refrains for Moving Bodies: Experience and Experiment in Affective Spaces. Durham: Duke University Press.

McMains, J. E. (2006). Glamour Addiction: Inside the American Ballroom Dance Industry. Connecticut: Wesleyan University Press.

Oyebade, A. (2007). Culture and Customs of Angola. Westport: Greenwood Press.

Parviainen, J. (2002). Bodily Knowledge: Epistemological Reflections on Dance. Dance Research Journal, 34 (1), pp. 11-26.

Potter, C. (2008). Senses of Motion, Senses of Self: Becoming a Dancer. Ethnos Journal of Anthropology, 73 (4), pp. 444-465.

Savigliano, M. E. (1995). Tango and the Political Economy of Passion. Oxford: Westview Press.

Schneider, B. (2013). Heteronormativity and Queerness in Transnational Heterosexual Salsa Communities. Discourse \& Society, 24 (5), pp. 553-571.

Sklar, D. (2000). Reprise: On Dance Ethnography. Dance Research Journal, 32 (1), pp. 70-77.

Sklar, D. (2001). Dancing with the Virgin: Body and Faith in the Fiesta of the Tortugas. New Mexico and Oakland: University of California Press.

Steps Dance Studio. (2016). Classes [online] Available at: http://stepsdancestudio. com/classes/ [10 Sept. 2016].

Stewart, K. (2007). Ordinary Affects. Durham: Duke University Press.

Tan, Q.H. (2013). Flirtatious Geographies: Clubs as Spaces for the Performance of Affective Heterosexualities. Gender, Place and Culture, 20 (6), pp. 718-736.

Tornqvist, M. (2013). Tourism and the Globalization of Emotions: The Intimate Economy of Tango. New York: Routledge. 